\title{
Closure of primate lab angers both researchers and critics
}

[WASHINGTON] The best known primate research centre in the north-eastern United States is to close at the end of December. The move leaves researchers in New York with no convenient access to primates, and animal rights activitists still angry over the shipment of half the former chimpanzee population of the Laboratory for Experimental Medicine and Surgery in Primates (LEMSIP) to a facility operated by the Coulston Foundation in New Mexico.

New York University (NYU) pledged to find retirement homes for LEMSIP's occupied the office of Jay Oliva, the university's president, overnight on 10 November. But last week NYU informed staff at LEMSIP that the facility will close for good on 31 December, after negotiations for its purchase by the Aaron Diamond AIDS Research Center had broken down.

According to sources close to the negotiations, NYU had wanted $\$ 1.1$ million for the facility, located at Tuxedo, 40 miles northwest of New York. But Aaron Diamond was only prepared to pay half this sum.

The closure marks the end of a saga that began two years ago, when NYU sacked Jan Moor Jankowski, the then director of LEMSIP, and said that it would transfer the facility and its animals to Coulston (see Nature 376, 543; 1995).

Aaron Diamond had been negotiating to buy the facility when the Coulston deal was announced. The AIDS research centre subremaining 28 chimpanzees after students

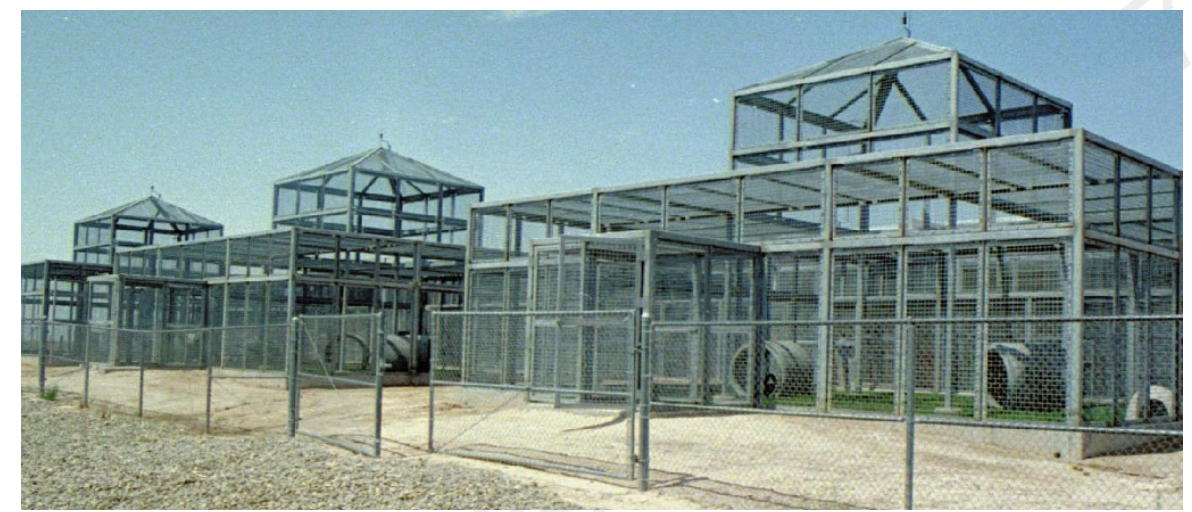

Home from home: the Coulston Foundation in New Mexico, to which chimpanzees have been moved. sequently severed its affiliation with NYU, and most of its researchers - including David Ho, its director - left NYU to take up faculty positions with Rockefeller University in New York.

Animal rights activists, who have long accused Coulston of mistreating chimpanzees, attacked the proposed transfer. And Jankowski sued NYU for \$17 million, alleging that he was being persecuted by the university for "whistle-blowing" on another researcher's work, which he considered unethical (see Nature 382, 746; 1996). The case is still being considered by a New York judge.

Although NYU and Coulston failed to agree terms for the transfer of LEMSIP itself, 100 chimpanzees were transferred to Coulston's New Mexico facility and another 100 were retired, leaving the current population of 28 animals. Meanwhile, Jankowski and

\section{Gingrich urges doubling of health funds}

[WASHINGTON] Newt Gingrich, the Speaker of the US House of Representatives, last week joined a growing band of prominent politicians calling for a doubling of government spending on biological and biomedical research.

Addressing a meeting in Georgia on women's health issues, Gingrich, the senior Republican in the House, said that such a move would contribute towards "the explicit goal of making the United States the primary producer of health care information in the world".

But, he added, reaching that goal should include a "dramatic overhaul" of the National Institutes of Health (NIH), which he said should be more transparent and more aggressive in using information technologies to publicize its work. "People ought to be able to get information faster and more openly," said Gingrich.
"I want the National Institutes of Health to become much more of an Internet and information-age-oriented system with a total transparency so that people can know what's being applied for, what's available, what kind of research is going on."

Gingrich said that a maximum of 18 months should elapse before doctors are told about new treatments and drugs. $\mathrm{He}$ proposed an Internet site continually updated to give push-button access to new scientific and medical information.

Diane Wax, director of legislative activities at NIH, says the agency is already making more medical information available to doctors and patients through the Internet. "We're doing much more than he's aware of." But, she adds, with millions of people not owning computers, "we can't make the Internet the only source of information for the public". other researchers at LEMSIP have formed an informal alliance with animal rights activists, including groups that oppose all animal experimentation, to attack NYU's management of LEMSIP.

"When I was approached by anti-vivisectionists and they wanted to know what I was doing, I'd let them know that it was important research," says Jankowski. Disagreements about animal treatment "can be solved amicably," he adds. "It doesn't have to be all about barbed wire and security guards."

LEMSIP's closure will mean that there is no primate research facility left in the New York area. Preston Marx, a virologist at Aaron Diamond whose recent work includes confirmation that the use of progesterone implants can speed transmission of HIV-like viruses between macaques (see Nature Medicine 2,1084 ; 1996), is now arranging to transfer his 140 macaques to a primate facility elsewhere in the United States.

Marx, a staff researcher at Aaron Diamond and a professor at NYU, plans to stay in New York temporarily after vacating his laboratory at LEMSIP, but will probably have to move to another part of the country to continue his work. "This is a great loss for the New York area," he says.

After the 10 November protest, Robert Berne, NYU's vice-president for academic development, promised that half of the remaining 28 chimpanzees would be retired this year and the rest later on, and that none would go to Coulston. He also said that Oliva would ask the senate academic affairs committee to "assess the desirability" of putting more students on the university's animal care committee.

But Berne says that the remaining chimpanzees were all going to be retired anyway. "I don't think we backed down at all," he says, adding that the protesters left Oliva's office because otherwise "they would have been expelled from the school". ColinMacilwain 